Original Article

\title{
Pattern and Practice of Pediatric Neurosurgical Procedures - An analysis of One - Year Initial Experience at Resource Challenged Setup of Children Hospital, Faisalabad
}

\author{
Faisal Feroz Rana ${ }^{1}$, Mazhar Mahmood ${ }^{2}$, Uzma Amin ${ }^{3}$ \\ Department of Neurosurgery, ${ }^{1}$ Children Hospital, Faisalabad, ${ }^{2}$ Orthopaedic Department, Allied Hospital, \\ Faisalabad, ${ }^{3}$ Lahore General Hospital, Lahore - Pakistan
}

\begin{abstract}
Objective: To study the Pattern and Practice of Pediatric neurosurgical procedures during one year among patients presenting to Children Hospital, Faisalabad.

Materials and Methods: Retrospective case series of 778 consecutive cases admitted in Pediatric Neurosurgery Department, Children Hospital, Faisalabad over one year (October 2019- September 2020). Patients of age less than 15 years, any gender, admitted in Pediatric Neurosurgery ward for management were included and studied for their demographic data hospital stay, a procedure done and outcome.
\end{abstract}

Results: A total of 778 patients who required some neurosurgical intervention were admitted, 725 underwent various types of procedures and the remaining were treated conservatively. 320 (44.14\%) were male and 405 (55.86\%) were female. The age range was 20 days to 13 years. The most common diagnosis was hydrocephalous, and then was Meningomyelocele (MMC). The first three common procedures performed included monitoring of Cerebrospinal fluid (CSF) in $36 \%$ of cases, Placement of shunt (21\%), and placement of external ventricular drain (EVD) in $13 \%$ of cases of cerebrospinal fluid (CNS) infections in patients of hydrocephalous.

Conclusion: Pattern of presentation of pediatric neurosurgical cases take in almost all types of diseases like neural tube defects, hydrocephalous, cranial trauma, tumors, cysts, and infections but surgical procedures in routine practice in Faisalabad district cover mainly hydrocephalous and its complications. Endoscopic or advanced procedures are not commonly practiced due to multiple factors but existing constraints do not prevent the best management of pediatric neurosurgery patients.

Keywords: Pediatric Neurosurgery, Neurosurgical Procedures.

Corresponding Author: Uzma Amin

Lahore General Hospital

Lahore

Email: uzmaamindermatologist@gmail.com
Date of Revision: 20-12-2021

Date of Acceptance: 30-12-2021

Date of Online Publishing: 31-12-2021

Date of Print: 31-12-2021

Date of Submission: 01-11-2021

DOI: $10.36552 /$ pjns.v25i4.625 


\section{INTRODUCTION}

In developing countries like Pakistan, an important focus of the health care delivery system is the high infant and maternal mortality rates; such mortalities and morbidities are due to infectious diseases like tuberculosis, malaria, or prematurity. ${ }^{1}$ Therefore, neurosurgical conditions although they are related to and result from many congenital disorders these are not considered among prior health problems. Even in the field of surgical specialties, neurosurgery particularly pediatric neurosurgery is neglected due to compromised facilities in emergency and critical care units. According to global reports, on average neurosurgeons performs 245 cases annually but the burden is more in underdeveloped countries due to the scarcity of neurosurgeons. ${ }^{2}$

Currently, a pediatric neurosurgical care facilityin Pakistan that may fulfill international standards and protocols is mostly unavailable especially for the rural population because these services are limited to the main cities of Pakistan only. Even in these centers, there are lots of problems like a limited number of trained staff, inadequate diagnostic and operative equipment. To add this, patients have to wait for long waiting before being operated upon for neurosurgical problems thus leading to an increase in their morbidity and mortality. Many patients are forced to bear the expenses of private consultations or referrals to other cities or even foreign countries for definite surgical treatment. ${ }^{3}$

Given this inadequate provision of neurosurgery care, Children Hospital Faisalabad (CHF) established a pediatric neurosurgical unit in April 2019 which was intended to cover the population of this third big city of Pakistan and its peripheral zones.

To date, clinical data about the burden of pediatric neurosurgical problems and the pattern of common neurosurgical procedures in the biggest province of Pakistan is lacking. Khan Z et $\mathrm{al}^{4}$ have described patterns of pediatric cases of neurotrauma in Peshawar, KPK but that lacks data about surgical care of those patients. Asif $\mathrm{M}^{5}$ in his study in Sahiwal has described the management of hydrocephalous patients only. Agrawal $A^{6}$ in Nepal studied 914 cases for neurosurgical management over one year.

This article describes various procedures performed in pediatric neurosurgical cases presenting to pediatric neurosurgery department with different disorders and it was analyzed over an initial one year at resource-poor setup having only one qualified neurosurgeon and limited working staff. It also describes future perspectives for pediatric neurosurgical care in Eastern Punjab, Pakistan.

\section{MATERIALS AND METHODS}

\section{Study Design and Setting}

A retrospective case series of consecutive cases were conducted Pediatric Neurosurgery Department of Children Hospital, Faisalabad. The study was done over one year (October 2019 November 2020).

\section{Sample Size}

The study comprised 778 cases of Pediatric neurosurgery disorders.

\section{Inclusion Criteria}

Patients of age less than 15 years of either gender who got admitted in Pediatric department. The neurosurgery ward for management was included in the study.

\section{Exclusion Criteria}

Patients who shifted to other departments for surgical management were excluded from the study. 


\section{Data Collection Procedure}

The study was conducted after approval from the hospital ethical committee.

The clinical record of patients who were admitted to the indoor ward of the pediatric neurosurgery department was reviewed. Demographic data was noted. Clinical data like presenting symptoms, findings on clinical examination, diagnosis, and type of conservative or surgical management were noted. Record of various types of operations, length of hospital stay, and the outcome were also noted to study the pattern of various types of diagnosis with their respective type of surgical procedure done over one year period.

\section{Data Analysis}

Data was entered \& analyzed through SPSS Version 25. Table and graphs were made. Data was stratified for the age of patients and outcome to address effect modifiers. Frequency \& percentages were calculated for variables like type of procedure and diagnosis. Stratification with age, gender, post-operative complications, and length of hospital stay was done to see the relationship among various variables.

\section{RESULTS}

A total of 778 patients who required some neurosurgical intervention were admitted, 725 underwent various types of procedures, and the remaining were treated conservatively.

\section{Gender Distribution}

Among the patients, 320 (44.14\%) were male and 405 (55.86\%) were female. M:F ratio was 1.4 . Table 1 shows frequencies and percentages of both genders.

\section{Age Distribution}

The mean age was 1.12 years with a Standard deviation of 1.85 and the age range was 20 days old to 13 years old.

\section{Types of Diagnosis and Procedures}

The most common diagnosis was hydrocephalous, and then was Meningomyelocele (MMC). Table 2 illustrates the details of various types of diagnosis of neurosurgical disorders for which different procedures were performed and their respective outcome (Table 2). Table 3 shows the comparison of males and females concerning the different procedures performed. The first three common procedures performed included monitoring of Cerebrospinal fluid (CSF) in 36\% of cases, Placement of shunt (21\%), and placement of external ventricular drain (EVD) in $13 \%$ of cases of cerebrospinal fluid (CNS) Infections in patients of hydrocephalous. Post-operative complications included shunt sepsis (08\%), Shunt displacement (12\%), CSF leak (15\%) and wound infection (5\%).

Table 1: Gender Distribution of Patients.

\begin{tabular}{lcc} 
Gender & Frequency & Percentage \\
Female & 405 & $55.86 \%$ \\
Male & 320 & $44.14 \%$ \\
Total & $\mathbf{7 2 5}$ & $\mathbf{1 0 0 . 0 0 \%}$ \\
\hline
\end{tabular}

Table 2: Types of Diagnoses and their outcome.

\begin{tabular}{lccccc|} 
Diagnosis & Improved & Static & Worse & Died & Improved \\
Brain Tumor & 0 & 1 & 0 & 0 & 0 \\
NTD - Encephalocele & 4 & 1 & 2 & 0 & 57.1 \\
Shunt Blockage & 21 & 3 & 2 & 1 & 77.8 \\
CNS Infections & 25 & 5 & 1 & 0 & 80.6 \\
NTD - Lipomeningocele & 9 & 1 & 1 & 0 & 81.8 \\
\hline
\end{tabular}




\begin{tabular}{|c|c|c|c|c|c|}
\hline NTD - Meningocele & 9 & 2 & 0 & 0 & 81.8 \\
\hline NTD - Pina Bifida & 7 & 1 & 0 & 0 & 87.5 \\
\hline Spine Tumor & 7 & 1 & 0 & 0 & 87.5 \\
\hline Other & 7 & 0 & 1 & 0 & 87.5 \\
\hline Hydrocephalous & 398 & 42 & 5 & 0 & 89.4 \\
\hline NTD - Meningomyelocele & 63 & 7 & 0 & 0 & 90 \\
\hline $\mathrm{CSDH}$ & 19 & 2 & 0 & 0 & 90.5 \\
\hline Scalp Abscess & 12 & 1 & 0 & 0 & 92.3 \\
\hline CNS Trauma & 37 & 1 & 0 & 1 & 94.9 \\
\hline CNS Tumor & 1 & 0 & 0 & 0 & 100 \\
\hline CSF Leak & 4 & 0 & 0 & 0 & 100 \\
\hline NTD - Tethered Cord & 8 & 0 & 0 & 0 & 100 \\
\hline Scalp Cyst & 4 & 0 & 0 & 0 & 100 \\
\hline \multicolumn{6}{|l|}{ Sample size $=778$} \\
\hline \multicolumn{6}{|l|}{$\mathrm{DF}=51$} \\
\hline \multicolumn{6}{|l|}{ Phi effect $(\Phi)=0.350893$} \\
\hline \multicolumn{6}{|l|}{$x^{2}=88.28$} \\
\hline \multicolumn{6}{|c|}{$\mathrm{p}$-value $=0.0009293$} \\
\hline \multicolumn{6}{|c|}{ The test statistic $\chi^{2}=88.28$ which is not in the $95 \%$ region of acceptance } \\
\hline
\end{tabular}

Table 3: Details of various Types of Procedures in Both Genders.

\begin{tabular}{lccc} 
Type of Procedure & Male & Female & Total \\
Aspiration & 0 & 1 & $1(0.14 \%)$ \\
Cranial tap & 1 & 0 & $1(0.14 \%)$ \\
Excision & 1 & 0 & $1(0.14 \%)$ \\
Skull traction & 0 & 1 & $1(0.14 \%)$ \\
Tumor removal & 1 & 1 & $2(0.28 \%)$ \\
Drainage & 0 & 3 & $3(0.41 \%)$ \\
Laminectomy & 2 & 2 & $4(0.55 \%)$ \\
Other & 6 & 1 & $7(0.96 \%)$ \\
Stitch removal & 5 & 5 & $10(1.38 \%)$ \\
Elevation of DSF & 5 & 10 & $15(2.07 \%)$ \\
Pus Drainage & 7 & 11 & $18(2.50 \%)$ \\
Pressure Monitoring & 14 & 7 & $21(2.89 \%)$ \\
VP Shunt-Revision & 12 & 13 & $25(2.89 \%)$ \\
Wound debridement & 11 & 21 & $32(4.41 \%)$ \\
Burr hole & 16 & 19 & $35(4 / 82 \%)$ \\
NTD repair & 20 & 42 & $62(8.54 \%)$ \\
EDV & 52 & 42 & $94(21.95 \%)$ \\
VP shunt-new & 75 & 80 & $155(21.35 \%)$ \\
CSF Tap & 93 & 146 & $239(32.92 \%)$ \\
\hline
\end{tabular}

Table 4: Outcome in Various Age Groups.

\begin{tabular}{|cccccc} 
Age & Improved & Static & Worse & Died & $\begin{array}{c}\text { Not } \\
\text { Defined }\end{array}$ \\
Below 1 & 531 & 58 & 9 & 1 & 8 \\
$1-5$ & 87 & 9 & 2 & 0 & 0 \\
$6-15$ & 17 & 1 & 1 & 1 & 0 \\
\hline
\end{tabular}

Table 5: Effect of Hospital Stay on the Outcome of Patients.

\begin{tabular}{|l|c|c|c|c|c|}
\hline Group & Improved & Static & Worse & Died & Total \\
\hline$<7$ & 612 & 56 & 9 & 1 & 678 \\
\hline$>7$ & 24 & 12 & 3 & 1 & 40 \\
\hline Total & $\mathbf{6 3 6}$ & $\mathbf{6 8}$ & $\mathbf{1 2}$ & $\mathbf{2}$ & $\mathbf{7 1 8}$ \\
\hline $\begin{array}{l}\text { Chi square }=38.87 \\
\text { DF }=3 \\
p=0.00001 \\
\text { Result is significant at 5\% level }\end{array}$ \\
\hline
\end{tabular}

\section{Outcome and Followup}

$9 \%(n=68)$ did not improve, $0.2 \%(n=2)$ died. No mortality was seen in patients of age $1-5$ years. Table 4 shows the details of outcome classified into four types i.e. improved, static, worse, dead, and not defined (Table 4). Whereas table 5 describes the relationship of hospital stay in various outcomes.

All operated were examined at follow-up on the $10^{\text {th }}$ postoperative day and then at monthly intervals for 3 months. Fifty - four patients were lost tofollow-up but these didn't include patients who had undergone VP shunt placement therefore we had good observation of the outcome of such cases. 


\section{Postoperative Complications}

These included shunt sepsis (08\%), Shunt displacement (12\%), CSF leak (15\%), and wound infection (5\%).

On bivariate logistic regression analysis, type of surgery, diagnosis, duration of hospital stay $(P=0.00001)$ were significantly correlated with outcome (Table 5).

Procedures that were performed very few included removal of brain tumor $(n=2)$, surgery for craniosynostosis $(n=1)$, Laminectomy $(n=2)$, and removal of teratoma of the back $(n=1)$. We had no case of aneurysm surgery during this one year and no case was treated by endoscopic third ventriculostomy (ETV).

\section{DISCUSSION}

This study was conducted on patients of pediatric neurosurgical cases who were admitted to and operated on at CHF. This hospital receives pediatric patients from all over Punjab province because of its location in the third big city of Pakistan. The pediatric neurosurgery department here has two operation days per week for elective cases only. Emergency care is limited to conservative management only due to lack of anesthesia staff and has only one qualified pediatric neurosurgeon available round the clock.

There are 5 Intensive Care unit (ICU) beds provided to pediatric neurosurgery patients and the neurosurgery ward has 10 beds. Outpatient services and operative treatments are provided on a twice - weekly basis. All these services are provided by only the certified pediatric neurosurgeon. The nursing staff comprises 2 staff nurses. The most common pathological diagnosis was hydrocephalous which comprised $61 \%$ of cases. This finding correlates with that of the study done in Sahiwal, Pakistan which also showed hydrocephalous as the commonest problem in pediatric neurosurgical patients. ${ }^{5}$ Our observation is contrary to that of Agrawal $A^{6}$ who found $69 \%$ cases of craniocerebral trauma in his study on 914 operated cases while Afolabi $^{7}$ observed $77 \%$ cases to be having congenital disorders. Therefore, our study results are in contrast to those stated above because we had only $8 \%$ cases of neurotrauma who were operated on. These constraints were due to lack of manpower which posed a great problem to managingall pediatric neurosurgery patients in emergency.

We also had to face a great burden of patients with spinal dysraphism and hydrocephalous who presented at our outpatient department run twice weekly. Moreover, such patients needed long-term management even with multiple admissions as compared to neurotrauma cases due to their treatment-related complications.

Out of 725 operated cases, $84 \%$ cases were below 1 year, 13\% were between $1-5$ years, and $2.75 \%$ were above 5 years. The worse outcome was seen in 9 cases below one year as compared to 2 in the age of $1-5$ years and no mortality was seen in $1-5$ years age group. Afolabi ${ }^{7}$ et al also observed $75 \%$ of neonates and infants. This stresses the need for proper neonatal ICU care because most of the cases are below 1 year of age who need critical post-operativecare to improve their outcome.

In our study, we managed one-third of cases of hydrocephalous by only monitoring CSF (35\%) because these had associated CSF infection. It was done in patients having hydrocephalous with MMC, tuberculous meningitis, arrested hydrocephalous or hydrocephalous due to brain atrophy. It was also indicated to assess CSF pressure and the outcome of VP shunt in the future. It was done with a drip set through the cranial tapin patients whose fontanelle was open and in the rest of the patients we used a Lumbar puncture needle. Terjae et $\mathrm{al}^{8}$ in their study on 71 pediatric patients with hydrocephalous and faltering shunt failure also found CSF monitoring to be with a very low - risk procedure and prevented the need for shunt revision in $49 \%$ of 
cases. $^{8}$

Shunt placement was our second common procedure performed on patients with hydrocephalous, neural tube defects, or tumors. $80 \%$ of our cases of neural tube defects had hydrocephalous also, so VP shunt was inserted beforerepair of the neural defect and also in those who were malnourished and could not be operated. We found that shunt had to be revised in $3 \%$ of cases because of malfunction, displacement, or infection.

In our one year of operative procedures of pediatric neurosurgery cases, external ventricular drainage comprised $12 \%$ of cases. EVD is essential in the early management of hydrocephalous and raised CSF pressure after subarachnoid hemorrhage, thus helpful in managing neurologically critical patients. ${ }^{9}$ Its placement influences the long-term outcome of the patient, rate of ventriculitis, the chance of delayed ischemia, need for VP shunt and intensive care unit (ICU), and hospital length of stay. ${ }^{10}$ We placed EVD in patients of hydrocephalous who had infected or blood - stained CSF. It was also used to deliver intraventricular antibiotics. EVD was replaced every third day.

The long list of patients awaiting operative treatment, lack of adequate equipment and manpower were the main factors forcing us to remain limited to VP shunt only instead of ETV or tumor surgery. Thus palliative treatment was chosen most of the time for tumors of the spine and brain or cases were referred. Our findings differ from those of Afolabi et al, who did VP shunting in $32 \%$ of cases, ETV in $16 \%$ of cases, and repair of neural tube defect in $27.5 \%$ cases. We had only $9 \%$ cases of repair of neural tube defects because we had to managethem conservatively because of various complications.

On bivariate logistic regression analysis, significant correlation of outcome was seen with type of $=0.00092)$, diagnosis $(p=0.00092))$ and length of stay in hospital $(p=0.00001)$. The patients having CNS tumors and those having less than 7 days stay in hospital after the surgical procedure showed a better outcome in form of clinical improvement. We found no effect of type of surgical procedure on the outcome of patients $(p$-value $=0.9)$. These results show that morbidity of patients after surgery is related to their age, health status, and diagnosis which can be lessened by reducing their stay in hospital after surgery. These results suggest that providing more complex neurosurgical procedures doesn't always assure improvement in the outcome of patients. Similar suggestions have been given by Benjamin $J$ et al who foundthe mortality rate in therange of $0.1-1.2 \%$, while in our study it was $0.2 \% .^{11}$

In our analysis of pediatric neurosurgical procedures over one year, we found that no case of ETV was done due to a lack of advanced equipment facilities. Results of a study by Abebe ${ }^{12}$ also differ markedly from our study and showed that burrhole procedure was the commonest performed procedure (17\%), VP shunt was done in $14 \%$ cases, tumor surgery in $12 \%$ of cases, and ETV was performed in $7 \%$ cases.

\section{Recommendations}

Further studies and detailed research on predisposing factors for hydrocephalous and neural tube defects in the population of Punjab province should be done to reduce the needfor neurosurgical procedures for such disorders.

ETV facilities, more operative staff including more neurosurgeons \& separate ICU for pediatric neurosurgery ward should be provided by Government in Children hospital of the third big city of Pakistan. Continued efforts in the health system are required to strengthen pediatric neurosurgical care all over Pakistan especially Punjab province.

Future studies about the analysis of various factors related to long - term outcomes in comparing different types of surgical procedures are needed in Pakistan to improve patient care. 
Combining higher - level procedures with basic pre and post-operative care is a key to reducingthe burden of morbidity of pediatric neurosurgery patients.

\section{Limitations}

Our study lacks data about cases operated in emergency operation theater because our setup is still lacking such facility and also due to inadequate certified staff regarding anesthesia, no emergency care can be provided in the evening and night hours. Therefore, cases of emergency were managed more conservatively than surgically in our study.

We did not evaluate the effect of comorbidities or postoperative biochemical complications on the outcome of operated patients. Moreover, long-term follow-up (more than 3 months) was not done.

\section{CONCLUSION}

The pattern of presentation of pediatric neurosurgical cases encompasses almost all types of diseases like neural tube defects, hydrocephalous, cranial trauma, tumors, cysts, and infections but surgical procedures in routine practice in Faisalabad district comprised CSF monitoring by CSF tap and VP shunt both indicated for hydrocephalous and its complications. This reflects routine neurosurgical procedures and endoscopic or advanced procedures are not commonly practiced due to multiple factors but existing constraints do not prevent the best management of pediatric neurosurgery patients.

\section{ACKNOWLEDGMENT}

It was a great privilege and honor to get the continuous guidance and motivation of Professor Dr. Malik Muhammad Nadeem to carry out this research.

\section{REFERENCES}

1. National Institute of Population Studies (NIPS) [Pakistan] and ICF. 2020. Pakistan Maternal mortality survey 2019: Key indicators Report. Islamabad, Pakistan, and Rockville, Maryland, USA: NIPS and ICF.

2. Park KB. Research in global neurosurgery: informing the path to achieving neurosurgical equity. Journal of Neurosurgery, 2019; 130 (4): 1053-4.

3. Sohail $A H$, Maan $M H$, Sachal $M$, Soban $M$. Challenges of training and delivery of pediatric surgical services in developing economies: a perspective from Pakistan. BMC Pediatrics, 2019; 19 (1): 1-3.

4. Khan Z, AzamF, Sharafat S, Gul S, Shahzad F. Patterns, Frequency and Gender Dominance in Paediatric Neuro-trauma in a Tertiary Care Hospital in Peshawar. Pakistan Journal of Neurological Surgery, 2020; 24 (2): 108-12.

5. Asif $M$, Younas A. Analysis of 200 cases of Hydrocephalous managed at DHQ teaching hospital, Sahiwal. Pak. J. of Neurol Surg. 2018; 22: 1.

6. Agrawal A, Kumar A, Agrawal C, et al. One year of neurosurgery in the eastern region of Nepal. Surgical Neurology, 2008; 69:652- 656.

7. Pediatric day-case neurosurgery in a resource challenged setting: Pattern and practice. Afolabi Muyiwa Owojuyigbe, 1.

8. Afolabi M, Edward O k, Anthony TA, Muyiwa AD, Chiazor W. Pediatric day case surgery in resource challenged setting: Pattern and practice. Afr J Paed Surg. 2016; 13 (2): 73-76.

9. Terje Saehle, Per Kristin Eide Intracranial pressure monitoring in pediatric and adult patients with hydrocephalous and tentative shunt failure: a single center experience over 10 years in 146 patients. J Neurosurg. 2015; 122 (5): 1076-86.

10. Carlos C, Omer D, J Claude H, Fernando RN, Geoffrey TM. Characterizing the response to CSF drainage in patients with an external ventricular drain: The pressure equalization ratio. Neurocut Care, 2019; 30 (2): 340-

11. Chung DY, Leslie-Mazwi TM, Patel AB, Rordorf GA. Management of External ventricular drains after sub arachnoid hemorrhage: A Multi - Institutional Survey. Neurocrit Care, 2017; 26 (3): 356-361. 
12. Benjamin J Kuo, Joao RN, Joseph RE, Emily RS. Perioperative outcomes for pediatric neurosurgical procedures: analysis of the National surgical Quality Improvement Programme - Pediatrics. J Neurosurg Pediatr. 2017; 19 (3): 361-371.
13. Abebe M, Munie T, Lende G, Bekele A. Pattern of neurosurgical procedures in Ethiopia: Experience from two major neurosurgical centers in Addis Ababa. East Cent Afr J Sur. 2011; 16 (1): 7-9.

\section{“Innumerable Types of Shark, Looming in The Deep Neurosurgery Sea, Waiting for a Poor Neurosurgeon to Bite Him..}

You May be Attacked by Ruptured Vessel, Spasm, Hematoma, Brain Swelling, Nerve Injury, etc."

\section{Additional Information}

Disclosures: Authors report no conflict of interest.

Ethical Review Board Approval: The study was conformed to the ethical review board requirements.

Human Subjects: Consent was obtained by all patients/participants in this study.

\section{Conflicts of Interest:}

In compliance with the ICMJE uniform disclosure form, all authors declare the following:

Financial Relationships: All authors have declared that they have no financial relationships at present or within the previous three years with any organizations that might have an interest in the submitted work.

Other Relationships: All authors have declared that there are no other relationships or activities that could appear to have influenced the submitted work.

\section{AUTHORS CONTRIBUTIONS}

\begin{tabular}{|l|l|l|}
\hline Sr.\# & Author's Full Name & Intellectual Contribution to Paper in Terms of: \\
\hline 1. & Faisal Feroz Rana & $\begin{array}{l}\text { Study design and methodology. Analysis of data and interpretation of results. Data } \\
\text { collection and calculations. }\end{array}$ \\
\hline 2. & Mazhar Mahmood & Analysis of data and quality insurer. Study design and methodology. \\
\hline 3. & Uzma Amin & Literature review, referencing paper writing and data calculations. \\
\hline
\end{tabular}

